\title{
Clinical Performance of Short-fiber-reinforced Resin Composite Restorations vs Resin Composite Onlay Restorations in Complex Cavities of Molars (Randomized Clinical Trial)
}

\author{
Rawda H ElAziz ${ }^{1}$, Mai M Mohammed², Hussien AF Gomaa ${ }^{3}$
}

\begin{abstract}
Background: Short-fiber-reinforced resin composite (SFRC) is a direct bulk fill resin composite specially indicated in large complex cavities. It is characterized by having high fracture toughness and load bearing capacity to decrease the incidence of fracture of the restoration.

Materials and methods: In two parallel groups ( $n=38$ restorations), 76 participants having complex proximal cavities with asymptomatic vital pulp were randomly enrolled in this trial and received either SFRC (Ever X Posterior, GC, Japan) covered by Gaenial posterior (GC, Japan) or chairside indirect restorations (Grandioso inlay system; VOCO, Germany) fabricated on a silicon die. Materials were applied according to the manufacturer instructions with the corresponding adhesive system. Only 67 participants completed the trial, which was assessed using the modified United States Public Health Service (USPHS) criteria by two independent blinded assessors at 6 months and 1 year follow-up visits.

Statistical analysis: Fisher's exact and Cochran's $Q$ tests were used to analyze inter- and intragroup comparisons, respectively. The significance level was set at $p \leq 0.05$.

Results: No statistically significant difference was observed between both tested groups for all USPHS criteria at different follow-up periods except for marginal integrity favoring the SFRC at 12 months when the difference became significant $(p<0.001)$, and color match favoring the nanohybrid indirect resin composite restorations with significant difference in scores at all follow-up intervals $(p<0.001)$ was found. Cochran's $Q$ test showed significant differences within the same technique during the follow-up period for some criteria.

Conclusion: Direct SFRC and indirect nanohybrid resin composite complex proximal restorations showed an acceptable clinical performance along the 1 year follow-up period.

Clinical relevance: Direct SFRC restorations could be a viable treatment option for complex restorative cases.

Keywords: Chairside indirect restorations, Direct vs indirect resin composite restorations, Randomized clinical trial, Short-fiber-reinforced resin composite restorations.

The Journal of Contemporary Dental Practice (2020): 10.5005/jp-journals-10024-2785
\end{abstract}

\section{INTRODUCTION}

Restoring large complex cavities is often encountered with several clinical challenges such as difficulty in accessibility, and high skills needed to control the anatomical form during restoration is subjected to more stresses. ${ }^{1}$ Indirect resin composite onlays have been proposed as one of the treatment options for treating these cases. They are usually lab processed; nevertheless, they can be made in one appointment through computer added designing (CAD)/computer added manufacturing (CAM) technology or by flexible model technique (semidirect technique) ${ }^{2}$ even though still this approach needs more procedural steps relative to the direct approach and more cost.

One of the advancements in resin composite technology to support its use in complex clinical situations directly is the evolution of Short-fiber-reinforced resin composite (SFRC) material where the filler system is potentiated with short electrical E-glass fibers to resist propagation of the crack, thus improving fracture toughness and preventing brittle fracture of the restoration. ${ }^{3}$ Short-fiber-reinforced resin composite (Ever X Posterior, GC Corp., Tokyo, Japan) is used as a bulk fill dentine substitute at highstress bearing areas. It can be packed in bulk up to $4 \mathrm{~mm}$ depth of cure with characterized low polymerization shrinkage. ${ }^{4}$ Thus, it allows making a direct complex onlay restoration a possible option, offering fewer procedural steps and effort over the indirect approach. ${ }^{3}$ Although many experimental studies and clinical
${ }^{1-3}$ Conservative Dentistry Department, Faculty of Dentistry, Cairo University, Cairo, Egypt

Corresponding Author: Rawda H ElAziz, Conservative Dentistry Department, Faculty of Dentistry, Cairo University, Cairo, Egypt, Phone: +20 (002)01001097200, e-mail: rawda.hesham@dentistry.cu.edu.eg

How to cite this article: ElAziz RH, Mohammed MM, Gomaa HAF. Clinical Performance of Short-fiber-reinforced Resin Composite Restorations vs Resin Composite Onlay Restorations in Complex Cavities of Molars (Randomized Clinical Trial). J Contemp Dent Pract 2020;21(3):296-303.

Source of support: Funding is accepted from VOCO, Cuxhaven, Germany. It supplied the materials used in the comparator group (indirect nanohybrid resin composite)

Conflict of interest: None

studies investigated the performance of $\mathrm{SFRC}_{1}{ }^{3-7}$ there is a gap of knowledge owing to the absence of any randomized clinical trials (RCTs) validating its clinical performance; in addition, no RCT has been published up till now comparing direct SFRC vs indirect resin composite restorations as reported by a recent systematic review. ${ }^{8}$

Thus, this RCT was proposed to evaluate the clinical performance of direct SFRC restorations vs indirect nanohybrid resin composite onlays in complex proximal cavities of molar teeth over 1 year. The proposed hypothesis was null. 


\section{Materials and Methods}

This prospective, randomized controlled trial was conducted between January 2018 and April 2019.

Eligible participants aged from 16 years to 55 years were those who had pulp asymptomatic large complex proximal carious cavities in molars or needed replacement of failed amalgam or resin composite restorations with good oral hygiene. Participants were excluded when they had teeth with signs and symptoms of irreversible pulpitis or pulp necrosis, with deep subgingival cavity margins that cannot be restoratively managed, evidence of any parafunctional habits, poor oral hygiene, heavy smokers, or temporomandibular disorders.

\section{Sample Size Calculation}

Based on the study ${ }^{9}$ where the primary outcome was clinical evaluation using modified USPHS criteria, if there is truly no difference between the two groups, then 68 restorations were required to be $80 \%$ sure that the limits of a two-sided $90 \%$ confidence interval would exclude a difference of more than $10 \%$ between the intervention and the comparator group. This number was to be increased to 76 ( $n=38$ per group) restorations to compensate for the possible losses during follow-up.

\section{Randomization, Sequence Generation, and Allocation Concealment}

In two parallel groups ( $n=38$ restorations), 76 participants ( 25 males; 51 females, the age of intervention group ( 31.13 years \pm 8.83 ) while the comparator group $28.13 \pm 6.06$ years), were randomly enrolled in this trial through a randomization web-based tool (https://www.random.org/). Random numbers were preserved in sealed opaque envelopes that were prepared by a contributor who was not involved anymore in the clinical trial. Informed consent was obtained from each participant after providing full explanation of the trial objectives and phases. Only 67 participants completed the trial follow-up times (see Flowchart 1). ${ }^{10}$

\section{Clinical Procedures}

All the clinical procedures were done by the same operator who was not blinded to the technique used due to the difference in application.

\section{Operative Procedures}

After full examination and radiographic assessment, local anesthesia was given (Artinibsa 4\% 1:100.000; Inibsa Dental S.L.U, Spain). The teeth were isolated by rubber dam (Sanctuary ${ }^{\circledR}$ Powder Free Latex Dental Dam, Malaysia). All cavities were prepared according to the principles of adhesive resin composite restorations with \#245 carbide bur and tapered stone with round end (Komet, USA) rotating at high speed with air/water-cooled handpiece. Any remaining carious dentin was excavated by an excavator (\#52; Dentsply Maillefer, Switzerland), according to the recent caries removal clinical recommendations. ${ }^{11}$ Cuspal tipping for not less than $2 \mathrm{~mm}$ clearance was done by a wheel stone (\#909, Komet, USA) for the weak cusps whose thickness is less than $2 \mathrm{~mm}$ measured by a caliper.

\section{Restorative Procedures (Table 1), Material Descriptions, Specifications, Compositions, and Manufacturers}

The SFRC Group (Figure 1)

- Appropriate precontoured sectional matrix with the corresponding ring (TOR VM, Russia) and a proper-sized wooden wedge were applied to restore the missing proximal wall.
- All the restorative materials were applied according to the manufacturer instructions. Selective enamel etching technique was done by etching the enamel margins only with 35\% phosphoric acid gel (Vococid; VOCO GmbH, Cuxhaven, Germany) for 20 seconds, rinsing with water for 20 seconds, and gently drying by blotting with cotton pellet. G-ænial Bond (GC, Tokyo, Japan) was applied and rubbed on the enamel and dentin surfaces using a disposable brush. It was left undisturbed for 10 seconds after the end of the application, then light cured by an LED light-curing unit $\left(>700 \mathrm{~mW} / \mathrm{cm}^{2}\right.$ ) (LED.F Curing Light, Woodpecker, China) for 10 seconds. The light intensity was checked periodically with the radiometer attached to the light-curing device.

- The missing peripheral walls were built first using the conventional microhybrid resin composite (G-ænial ${ }^{\circledR}$ Posterior, GC, Tokyo, Japan) and light-cured for 20 seconds. Then SFRC (Ever X Posterior, GC, Tokyo, Japan) was injected in bulk, i.e., about $4 \mathrm{~mm}$ thick layer and light cured for 20 seconds, leaving a 1- to 2-mm space for a surface layer of the conventional resin composite (G-ænial ${ }^{\oplus}$ Posterior, GC, Tokyo, Japan).

- Finishing was done using fine grit diamond stones (\#368EF, \#852EF, Komet, USA) and polishing by rubber points (Occlubrush $^{\mathrm{TM}}$, Kerr, Switzerland) after centric and eccentric occlusion checking.

\section{Indirect Nanohybrid Resin Composite Group (Fig. 2)}

- Cavity preparation was done following the same protocol previously discussed for the intervention group in addition to adjusting the walls to be with an approximately $15^{\circ}$ angle of occlusal divergence. ${ }^{12}$ The available interocclusal clearance was checked to be at least $2 \mathrm{~mm}$ in centric and during lateral movement.

- Immediate dentin sealing (IDS) was done by sealing the whole dentin with a two-step self-etch adhesive (Futurabond DC, VOCO, Cuxhaven, Germany) following manufacturer's instructions as follows: $35 \%$ phosphoric acid gel (Vococid, VOCO, Cuxhaven, Germany) was applied on the enamel margins only for 20 seconds, rinsed by water for 20 seconds, and gently dried by blotting with cotton pellet. While (Futurabond DC, VOCO, Cuxhaven, Germany) was applied by mixing 1 drop of liquid 1 and 1 drop of liquid 2 till homogenous mixture was obtained. This mix was applied and rubbed into the cavity for 20 seconds then gently air-dried for 5 seconds and light cured for 10 seconds. Then a thin layer of flowable resin composite material (GrandioSO Flow, VOCO, Germany) was applied all over the cavity and light cured for 20 seconds for cavity design optimization and cervical margins relocation, if needed.

- Alginate impression (Hydrogum 5; Zhermack SpA, Italy) was taken to working and the opposing arches then poured with the silicone die model material (Die Silicon, VOCO, Cuxhaven, Germany).

- On the silicon die, the resin composite restoration was incrementally fabricated using the nanohybrid resin composite (GrandioSo, VOCO, Cuxhaven, Germany). Each layer was $2 \mathrm{~mm}$ thick, which was light cured for 20 seconds. The fabricated restoration was finished and polished.

- In the patient mouth, the restoration was checked for proximal contacts, occlusion, and marginal fit.

- The restoration fitting surface was silanated (Ceramic bond, VOCO, Cuxhaven, Germany) and bonded (Futurabond DC, VOCO, 
Flowchart 1: CONSORT 2010 flow diagram

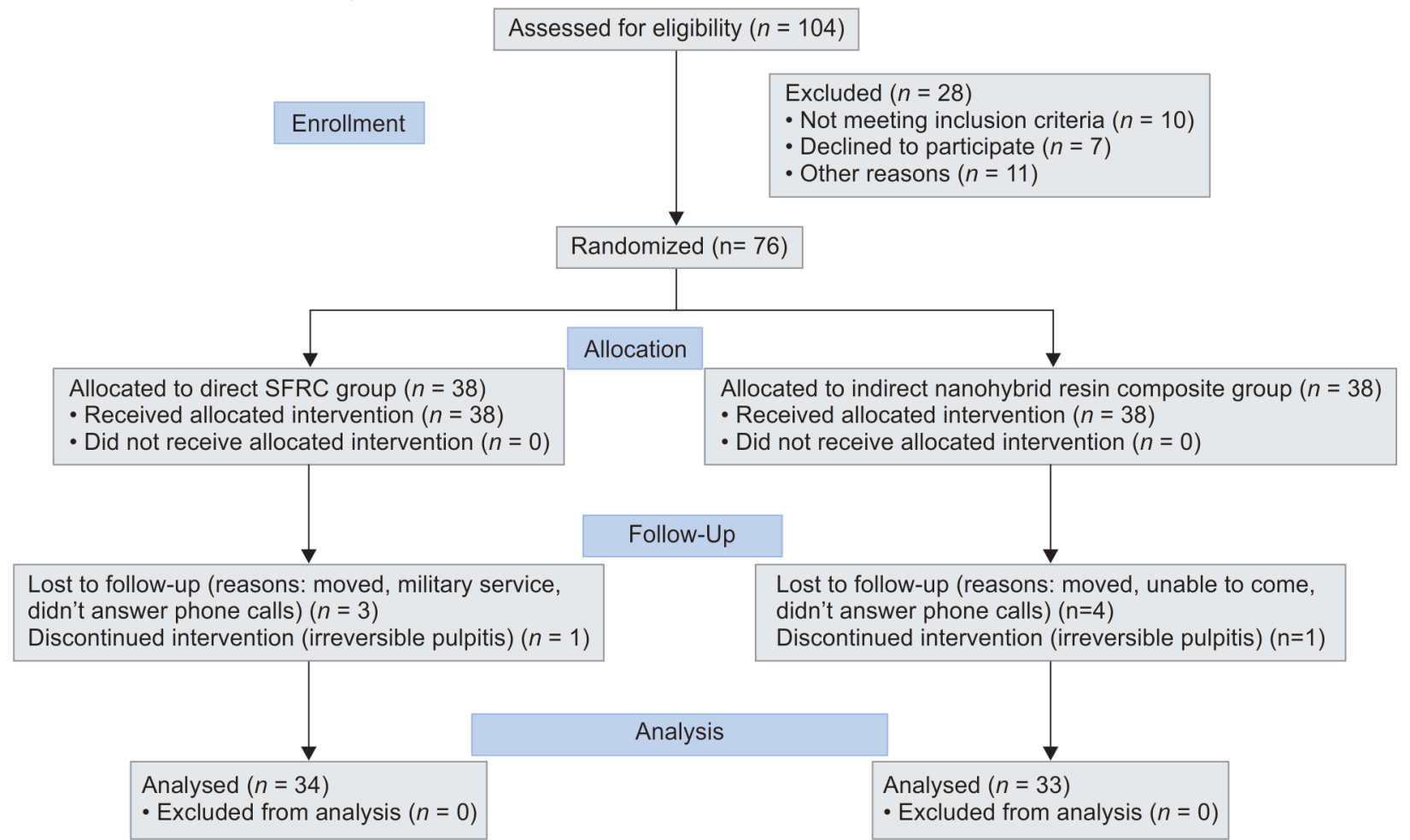

Cuxhaven, Germany), while the tooth was treated with the adhesive (Futurabond DC, VOCO, Cuxhaven, Germany) applied as previously described.

- Dual-curing adhesive resin cement (Bifix QM, VOCO, Cuxhaven, Germany) was ejected and applied into the preparation. The restoration was then placed in the cavity and checked for complete seating. The cement was tac light cured for only 2 seconds to facilitate the removal of the marginal excess. Then light curing was done from all surfaces each for 20 seconds for achieving the final set. Finally, finishing and polishing were done in the same manner as mentioned previously.

\section{Clinical Evaluation: Modified USPHS Criteria (Table 2)}

Restorations were evaluated clinically at 6 months and 12 months follow-up visits using modified USPHS criteria by two different trained blinded assessors, and any conflict in the given scores was resolved by discussion.

\section{Statistical Analysis}

Statistical analysis was performed with IBM SPSS ${ }^{\circledR}$ (SPSS Inc., IBM Corporation, NY, USA) Statistics Version 25 for Windows. Fisher's exact and Cochran's $Q$ tests were used to analyze inter- and intragroup comparisons, respectively. The significance level was set at $p \leq 0.05$ for all tests.

\section{Results (Table 3)}

Seventy-six participants were enrolled in this trial, and only 67 participants completed the trial. Lost to follow-up was because the participant moved to another place far from the hospital, did not answering phone calls or was admitted to military service. The interventions were discontinued in two participants due to the presence of signs and symptoms of irreversible pulpitis.
Independent $t$ test showed no significant difference between the age of the participants in both groups $(p=0.088)$. Fisher's exact test showed no significant difference in the number of affected tooth surfaces in both groups ( $p=0.120$ ).

For the intragroup comparison among the different follow-up periods, Cochran's $Q$ test showed no significant difference in the distribution of postoperative hypersensitivity scores between follow-up periods within the intervention ( $p=0.333$ ) or the comparator groups $(p=0.111)$. For the color match only in the intervention group, 12 restorations recorded bravo at baseline and at the follow-up periods, showing a significant difference $(p=1.000)$. While for the marginal integrity, no significant difference was observed in the distribution of scores between follow-up periods in the intervention group ( $p=0.074$ ); and for the control group, a significant difference was observed $(p<0.001)$. No significant difference was observed in the distribution of cavosurface marginal discoloration scores between follow-up periods in the intervention group ( $p=0.333)$; and for the comparator group, a significant difference was observed $(p=0.037)$.

All participants of both groups had a score of alpha for secondary caries-gross fracture-anatomic contour (wear)-surface texture from baseline until the end of the follow-up period.

For the intergroup comparison, no statistically significant difference was observed between both the tested materials for all USPHS criteria except for marginal integrity favoring the SFRC at 12 months when the difference became significant $(p<0.001)$, and color match favoring the nanohybrid indirect resin composite restorations as significant difference of scores at all follow-up intervals $(p<0.001)$ was found.

\section{Discussion}

According to a systematic review, ${ }^{13}$ the mean annual failure rate of direct posterior resin composite restorations for 10 years was $2.4 \%$ 
Clinical Performance of Fiber-reinforced Resin Composite Restorations in Molars

Table 1: Material descriptions, specifications, compositions and manufacturers

\begin{tabular}{|c|c|c|}
\hline Material & Specifications & Composition \\
\hline \multicolumn{3}{|c|}{ Direct short-fiber-reinforced resin composite system (GC, Tokyo, Japan) } \\
\hline Ever $\mathrm{X}$ posterior & $\begin{array}{l}\text { Short-fiber-reinforced resin } \\
\text { composite }\end{array}$ & BIS-GMA, TEGDMA, PMMA, discontinuous E glass fiber fillers, barium glass. \\
\hline Universal shade (LOT \#1704061) & & Filler loading 4.2 wt $\%, 53.6$ vol\% \\
\hline G-ænial bond (LOT\# 171281) & $\begin{array}{l}\text { One-component self-etching } \\
\text { light-cured adhesive }\end{array}$ & $\begin{array}{l}\text { HEMA-free, 4-MET, UDMA, TEGDMA, phosphoric acid monomer, acetone, } \\
\text { water, silanated colloidal silica, initiator }\end{array}$ \\
\hline G-ænial posterior & Microhybrid resin composite & Resin matrix: UDMA and dimethacrylate \\
\hline A2, A3 shade (LOT \#1702092) & & $\begin{array}{l}\text { Filler: free prepolymerized fillers strontium and lanthanide fluoride } \\
(16-17 \mu) \text { and fluoroaluminosilicate. Filler loading } 81 \mathrm{wt} \%\end{array}$ \\
\hline \multicolumn{3}{|c|}{ GrandioSO Inlay System (VOCO GmbH, Cuxhaven, Germany) } \\
\hline GrandioSO & Nanohybrid resin composite & Resin matrix: bis-GMA, TEGDMA, bis-EMA \\
\hline A2, A3 shade (LOT \#17024538) & & $\begin{array}{l}\text { Filler: } 1 \mu \text { glass ceramic fillers with } 20-40 \text { nm functionalized silicone dioxide } \\
\text { nanoparticles. Filler loading } 89 \text { wt } \%\end{array}$ \\
\hline \multirow[t]{2}{*}{ GrandioSO flow (LOT \#1702865) } & \multirow{2}{*}{$\begin{array}{l}\text { Nanohybrid flowable resin } \\
\text { composite }\end{array}$} & Resin matrix: bis-GMA, TEGDMA, bis-EMA \\
\hline & & $\begin{array}{l}\text { Filler: } 1 \mu \text { glass ceramic fillers with } 20-40 \mathrm{~nm} \text { functionalized silicone dioxide } \\
\text { nanoparticles. Filler loading } 80.2 \mathrm{wt} \% \text {. }\end{array}$ \\
\hline Vococid (LOT \#1702865) & Phosphoric acid etching gel & $\begin{array}{l}\text { Water, } 35 \% \text { phosphoric acid, synthetic amorphous silica, polyethylene } \\
\text { glycol, aluminum oxide }\end{array}$ \\
\hline \multirow[t]{2}{*}{$\begin{array}{l}\text { Futurabond DC (LOT \#1708519) } \\
\text { (LOT \#1708520) }\end{array}$} & $\begin{array}{l}\text { Two step dual cure self-etch } \\
\text { adhesive }\end{array}$ & $\begin{array}{l}\text { Liquid 1: acid modified methacrylate (methacrylate ester), HEMA, } \\
\text { camphorquinone. }\end{array}$ \\
\hline & & Liquid 2: water, ethanol, silicium dioxide \\
\hline Ceramic bond (LOT \#1647247) & Silane coupling agent & Phosphoric acid ester, trimethoxysilane, and acetone \\
\hline Bifix QM (LOT \#1647598) & $\begin{array}{l}\text { Dual-cured adhesive resin } \\
\text { cement }\end{array}$ & Bis-GMA, DMA, silica fillers, benzoyl peroxide; amines, pigment, additives \\
\hline Die silicone (LOT \#1704515) & Silicone model material & Addition curing silicon, polyvinyl siloxane-based material; catalyst \\
\hline Hydrogum 5 & $\begin{array}{l}\text { Fast setting alginate impres- } \\
\text { sion material }\end{array}$ & Potassium alginate, cristobalite, dipotassium \\
\hline Zhermack SpA & & Hexafluorotitanate, isopentyl acetate \\
\hline Badia Polesine, Italy & & \\
\hline
\end{tabular}

which is clinically accepted. Meanwhile, they found that the main risk factors for failure are patients with high caries risk profile or a high number of restored surfaces (complex cases).

Short-fiber-reinforced resin composite has been developed to be used in complex cases and high-stress bearing areas. According to a review of in vitro studies published in 2018, SFRC restorations showed improved failure mode and high load bearing capacity in relation to the conventional resin composite restorations. Also, they recommended SFRC to be one of the treatment options for large-size cavities (direct onlay). ${ }^{5}$

Grandioso inlay system (VOCO, Cuxhaven, Germany) is a chairside silicone die (flexible model technique) semidirect or indirect resin composite system. It was selected to offer the patient with indirect restorations that can be done in the same visit with good clinical performance. ${ }^{14}$ This technique was found to be a good substitute to restorations made by CAD/CAM technology, as it offered comparable marginal and internal fit, while being less time-consuming and more cost-effective. ${ }^{2}$

For the clinical assessment of the performance of the restorations, modified USPHS criteria were chosen because they are the most commonly used criteria for the evaluation of dental restorations among research studies according to a systematic review. ${ }^{15}$ Short-term follow-up periods 6 months and 1 year were selected to be published as interim results to assess the early clinical performance of the SFRC restorations especially that there was not any RCT published before about their performance; furthermore, they are functioning in threatening high-stress bearing areas, so early catastrophic failure should be quickly detected and managed. ${ }^{13}$

Regarding the results of the postoperative hypersensitivity, no statistically significant difference was observed between the two groups. Most of the participants reported the absence of the postoperative hypersensitivity. This could be attributed to that direct SFRC is characterized by having low polymerization shrinkage stresses, thus less strain on the margins and the tooth structure; ${ }^{16}$ while in the comparator group, IDS step has been proved by literature to reduce the postcementation sensitivity. ${ }^{17}$ Participants suffered from postoperative hypersensitivity might have a pulp threatening clinical depth that increases the incidence of having pain. ${ }^{18}$

Concerning the results of color match, a statistically significant difference was observed between the two groups favoring the indirect nanohybrid resin composite onlay restorations. This may be due to the characterized very translucent color of SFRC where the remaining thickness of the 1 to $2 \mathrm{~mm}$ (G-ænial Posterior, GC, Tokyo, Japan) layer at the depth of the pit and fissures could not conceal the deep color of the residual amalgam tattoo present or dark sclerotic dentin. This is unlike to the indirect nanohybrid resin composite restorations where the presence of multiple layers of the conventional resin composite material can mask this greyish color. Using a high chroma resin composite superstructure over SFRC or an underlying opaquer is recommended in cases of remaining deep stain at the base of the cavity to ensure the best esthetic results. 

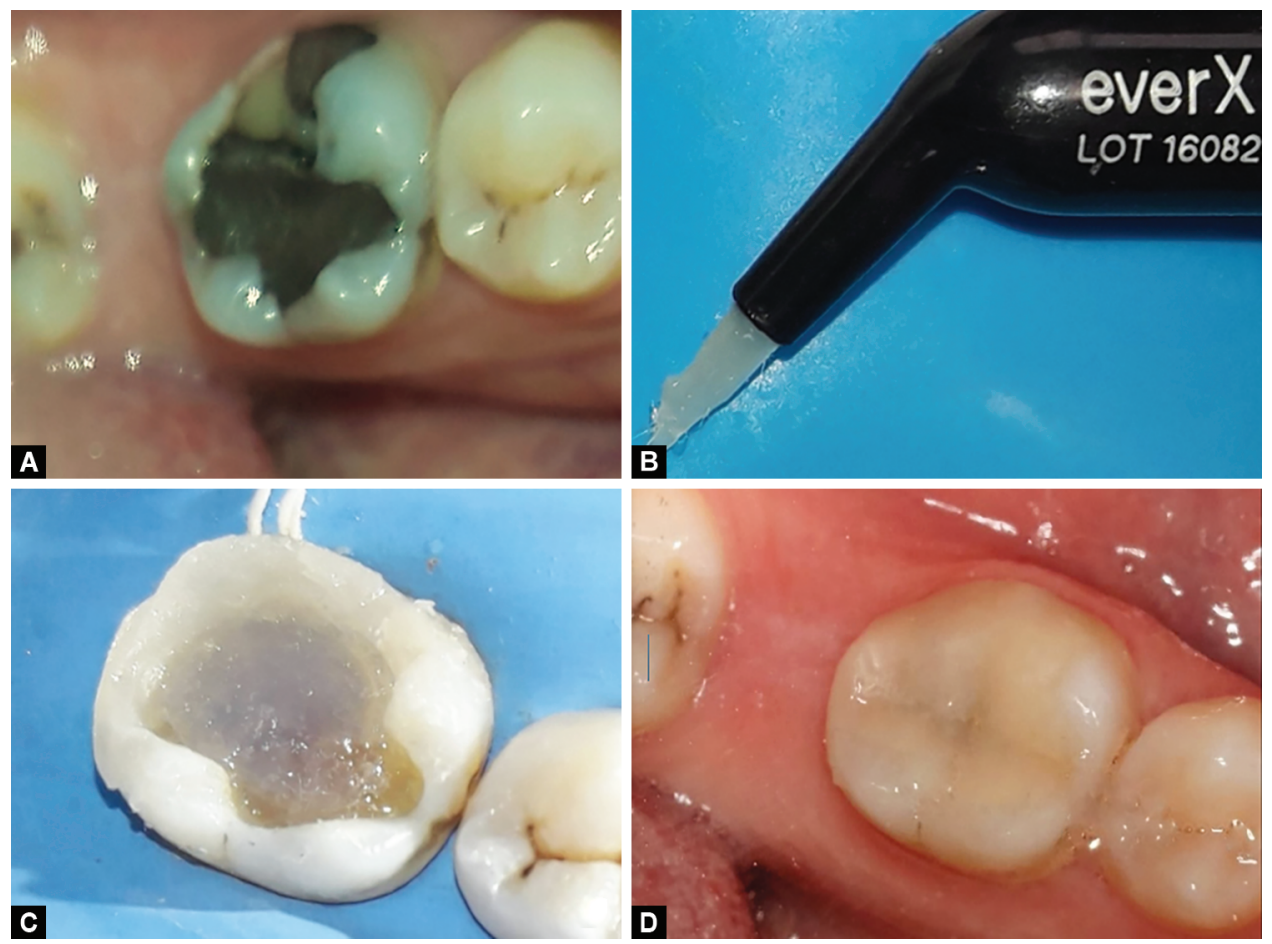

Fig. 1: (A) Photo of failed amalgam restoration in lower right first molar; (B) SFRC, Ever X posterior, GC, Tokyo, Japan (note how the fibers are projected from the increment); (C) SFRC packed in the center while the peripheries are from Gaenial posterior, GC, Japan; (D) Final direct SFRC restoration
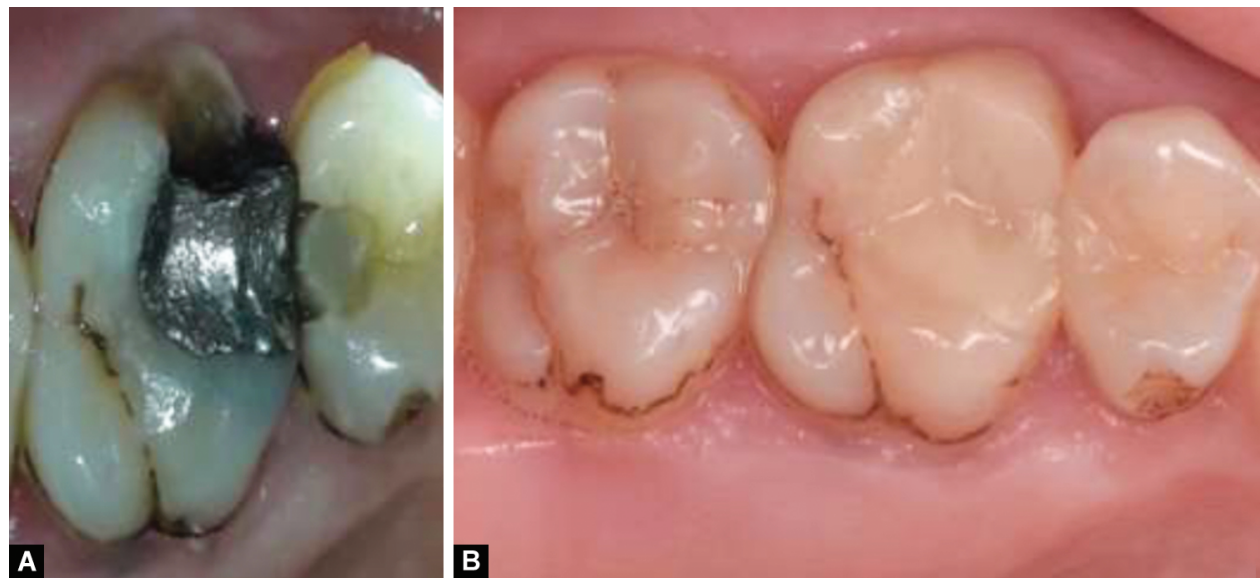

Fig. 2: (A) A preoperative photo of failed amalgam restoration in upper left first molar; (B) An indirect resin composite restoration. GrandioSO Inlay System (VOCO GmbH, Cuxhaven, Germany)

Regarding the results of the marginal integrity, a statistically significant difference was observed between the two groups favoring the SFRC group. This could be attributed to that indirect restorations are characterized by having multiple restorative phases where failure can occur between any phases leading to marginal opening, especially at the cement line unlike direct restorations where fewer phases are present and more control on the marginal adaptation. ${ }^{19,20}$

For the results of cavosurface marginal discoloration, no statistically significant difference was observed between the two groups. This could be associated with the presence of marginal leakage at the cement line or the adhesive layer ${ }^{21}$ also due to changes in the optical properties of the cementing material which is highly affected by the pigments absorbed from the patient diet. ${ }^{22}$

While for the results of secondary caries, none of the restorations demonstrated secondary caries after 1 year of observation. This could be due to the short-term observation period especially that the patient oral hygiene habits and caries risk are the primary factors that determine whether secondary caries would develop, regardless of the cavosurface margin condition, whether excellent, acceptable, or deteriorated; ${ }^{23,24}$ and in this study, good oral hygiene maintenance and caries control instructions were strongly recommended to the participants.

Regarding the results of gross fracture of the restoration both groups did not exhibit any fracture. Both the groups' materials are characterized by having improved mechanical characteristics $5^{5,14}$ and fractures of the restorative system is usually a long-term failure. ${ }^{13}$ Notably, patients with parafunctional habits were excluded in this study, and bruxism is one of the influencing patient risk factors affecting the failure rate of posterior resin composite restorations causing restoration fracture. ${ }^{13}$

Concerning the anatomic form (wear), both groups did not exhibit any surface wear. This is in accordance with the findings in a review of literature ${ }^{25}$ where it was found that a decline in finding 
Table 2: Modified USPHS criteria

\begin{tabular}{|c|c|c|c|}
\hline Criterion & Score & Description & Measuring method \\
\hline \multirow[t]{2}{*}{ Postoperative hypersensitivity } & Alpha & Absent & Patient interviewing \\
\hline & Charlie & Present & \\
\hline \multirow[t]{2}{*}{ Secondary caries } & Alpha & No caries present along the margins & Visual inspection with mirror \\
\hline & Charlie & $\begin{array}{l}\text { There is visual evidence of dark carious discoloration } \\
\text { along the restoration }\end{array}$ & \\
\hline \multirow[t]{3}{*}{ Gross fracture } & Alpha & Restoration is intact and fully retained & Visual inspection with mirror \\
\hline & Bravo & $\begin{array}{l}\text { Some portion of the restoration is still intact and can be } \\
\text { repaired }\end{array}$ & \\
\hline & Charlie & Restoration is completely fractured & \\
\hline \multirow[t]{3}{*}{ Color match } & Alpha & $\begin{array}{l}\text { The restoration matches the shade and translucency of } \\
\text { the adjacent tooth }\end{array}$ & Visual inspection with mirror \\
\hline & Bravo & $\begin{array}{l}\text { There is a mismatch in the shade and translucency, but it } \\
\text { is within the normal range of tooth shade }\end{array}$ & \\
\hline & Charlie & $\begin{array}{l}\text { The mismatch is beyond the normal range of the tooth } \\
\text { shades and translucency }\end{array}$ & \\
\hline \multirow[t]{3}{*}{$\begin{array}{l}\text { Cavosurface marginal discol- } \\
\text { oration }\end{array}$} & Alpha & $\begin{array}{l}\text { There is no visual evidence of any marginal discoloration } \\
\text { at the junction of the restoration and the adjacent tooth } \\
\text { structure }\end{array}$ & Visual inspection with mirror \\
\hline & Bravo & There is visual evidence of shallow marginal discoloration & \\
\hline & Charlie & $\begin{array}{l}\text { There is visual evidence of deep marginal discoloration } \\
\text { toward a pulpal direction }\end{array}$ & \\
\hline \multirow[t]{3}{*}{ Marginal integrity } & Alpha & $\begin{array}{l}\text { The explorer does not catch and there is no visible crev- } \\
\text { ice along the margin of the restoration. }\end{array}$ & $\begin{array}{l}\text { Visual inspection with mirror } \\
\text { and explorer }\end{array}$ \\
\hline & Bravo & $\begin{array}{l}\text { The explorer catches and there is visible evidence of a } \\
\text { crevice but the dentin or the base are not exposed }\end{array}$ & \\
\hline & Charlie & There is crevice defect extended to the dentin & \\
\hline \multirow[t]{3}{*}{ Anatomic contour (wear) } & Alpha & $\begin{array}{l}\text { The restoration is continued with the existing anatomic } \\
\text { form or slightly flattened }\end{array}$ & $\begin{array}{l}\text { Visual inspection with mirror } \\
\text { and explorer }\end{array}$ \\
\hline & Bravo & $\begin{array}{l}\text { A surface concavity is present. But the dentin or the base } \\
\text { is not exposed }\end{array}$ & \\
\hline & Charlie & $\begin{array}{l}\text { A surface concavity is present and the base and/or the } \\
\text { dentin is exposed }\end{array}$ & \\
\hline \multirow[t]{2}{*}{ Surface texture } & Alpha & Surface texture is similar to the adjacent enamel & Explorer \\
\hline & Bravo & Surface texture is rougher than the adjacent enamel & \\
\hline
\end{tabular}

wear as a reason for failure in the last decade due to the great advancement done in the technology of resin composites.

For the surface texture results, no restoration exhibited change in the surface texture. This could be attributed to the same finishing and polishing protocol used for the two groups that warranted long-lasting surface finish and polish. ${ }^{20}$

The American Dental Association released guidelines for adhesive resin composite materials in $2001 .{ }^{26}$ They stated that the restoration performance could be considered clinically acceptable when there is only $5 \%$ or less of the evaluated restorations was lost and no critical microleakage was found at the 6-month follow-up. ${ }^{14}$ Based upon the previous findings, both techniques offer clinically acceptable functioning restorations at 1 year. The proposed hypothesis is accepted.

\section{Strength Points of the Study}

- This is the first RCT validating SFRC clinical performance and to compare the two restorative materials with concern to direct vs indirect approach.
- Loss to follow-up did not exceed $15 \%$.

\section{Limitations of the Study}

- Short follow-up periods but further follow-up visits are scheduled.

- Operator blinding was not applicable due to different restorative techniques.

\section{Clinical Recommendations}

- Longer follow-up period is highly recommended to substantiate the current results of the study.

- Testing SFRC restorations in different clinical situations are advocated, e.g., endodontically treated teeth in patients with high occlusal stresses or to be tested against conventional layered resin composite restorations or indirect restorations fabricated on stone models to confirm their general performance. 


\begin{tabular}{|c|c|c|c|c|c|c|c|c|c|c|c|c|c|c|c|}
\hline \multirow{4}{*}{$\begin{array}{l}\text { Evaluation } \\
\text { criteria }\end{array}$} & \multirow[b]{4}{*}{ Score } & \multicolumn{12}{|c|}{ Follow-up } & \multicolumn{2}{|c|}{$\begin{array}{c}\text { Intragroup } \\
p \text { value }\end{array}$} \\
\hline & & \multicolumn{4}{|c|}{ Baseline } & \multicolumn{4}{|c|}{6 months } & \multicolumn{4}{|c|}{12 months } & \multirow[b]{3}{*}{ SFRC } & \multirow[b]{3}{*}{ Indirect } \\
\hline & & \multicolumn{2}{|c|}{ SFRC } & \multicolumn{2}{|c|}{ Indirect } & \multicolumn{2}{|c|}{ SFRC } & \multicolumn{2}{|c|}{ Indirect } & \multicolumn{2}{|c|}{ SFRC } & \multicolumn{2}{|c|}{ Indirect } & & \\
\hline & & $\%$ & $n$ & $\%$ & $n$ & $\%$ & $n$ & $\%$ & $n$ & $\%$ & $n$ & $\%$ & $n$ & & \\
\hline \multirow{3}{*}{$\begin{array}{l}\text { Postoperative } \\
\text { hypersensi- } \\
\text { tivity }\end{array}$} & Alpha & 100 & (34) & 100 & (33) & 97.10 & (33) & 93.90 & (31) & 97.10 & (33) & 93.90 & (31) & $0.333 \mathrm{NS}$ & $0.111 \mathrm{NS}$ \\
\hline & Charlie & 0 & $(0)$ & 0 & $(0)$ & 2.90 & $(1)$ & 6.10 & $(2)$ & 2.90 & $(1)$ & 6.10 & $(2)$ & & \\
\hline & $\begin{array}{l}\text { Intergroup } \\
p \text { value }\end{array}$ & - & & & & $0.489 \mathrm{NS}$ & & & & $0.489 \mathrm{NS}$ & & & & & \\
\hline \multirow[t]{4}{*}{ Color match } & Alpha & 64.70 & $(22)$ & 100 & (33) & 64.70 & $(22)$ & 100 & (33) & 64.70 & $(22)$ & 100 & (33) & $1.000 \mathrm{NS}$ & - \\
\hline & Bravo & 35.30 & $(12)$ & 0 & $(0)$ & 35.30 & $(12)$ & 0 & $(0)$ & 35.30 & $(12)$ & 0 & $(0)$ & & \\
\hline & Charlie & $0 \%$ & $(0)$ & 0 & $(0)$ & 0 & $(0)$ & 0 & $(0)$ & 0 & $(0)$ & 0 & $(0)$ & & \\
\hline & $\begin{array}{l}\text { Intergroup } \\
p \text { value }\end{array}$ & $<0.001^{*}$ & & & & $<0.001^{*}$ & & & & $<0.001^{*}$ & & & & & \\
\hline \multirow{4}{*}{$\begin{array}{l}\text { Marginal } \\
\text { integrity }\end{array}$} & Alpha & 100 & (34) & 100 & (33) & 97.10 & (33) & 84.80 & (28) & 88.20 & $(30)$ & 60.60 & (20) & $0.074 \mathrm{NS}$ & $<0.001^{*}$ \\
\hline & Bravo & 0 & $(0)$ & 0 & $(0)$ & 2.90 & (1) & 15.20 & (5) & 11.80 & (4) & 39.40 & (13) & & \\
\hline & Charlie & 0 & $(0)$ & 0 & $(0)$ & 0 & $(0)$ & 0 & $(0)$ & 0 & $(0)$ & 0 & $(0)$ & & \\
\hline & $\begin{array}{l}\text { Intergroup } \\
p \text { value }\end{array}$ & - & & & & $0.092 \mathrm{NS}$ & & & & $0.010^{*}$ & & & & & \\
\hline \multirow{4}{*}{$\begin{array}{l}\text { Cavosurface } \\
\text { marginal dis- } \\
\text { coloration }\end{array}$} & Alpha & 100 & (34) & 100 & (33) & 100 & (34) & 100 & (33) & 94.10 & $(32)$ & 87.90 & (29) & 0.333 NS & $0.037^{*}$ \\
\hline & Bravo & 0 & $(0)$ & 0 & $(0)$ & 0 & $(0)$ & 0 & $(0)$ & 5.90 & (2) & 12.10 & (4) & & \\
\hline & Charlie & 0 & $(0)$ & 0 & $(0)$ & 0 & $(0)$ & 0 & $(0)$ & 0 & $(0)$ & 0 & $(0)$ & & \\
\hline & $\begin{array}{l}\text { Intergroup } \\
p \text { value }\end{array}$ & - & & & & - & & & & $0.322 \mathrm{NS}$ & & & & & \\
\hline \multirow{3}{*}{$\begin{array}{l}\text { Secondary } \\
\text { caries }\end{array}$} & Alpha & 100 & (34) & 100 & (33) & 100 & (34) & 100 & (33) & 100 & (34) & 100 & (33) & - & - \\
\hline & Charlie & 0 & $(0)$ & 0 & $(0)$ & 0 & $(0)$ & 0 & $(0)$ & 0 & $(0)$ & 0 & $(0)$ & & \\
\hline & $\begin{array}{l}\text { Intergroup } \\
p \text { value }\end{array}$ & - & & & & - & & & & - & & & & & \\
\hline \multirow{3}{*}{$\begin{array}{l}\text { Surface } \\
\text { texture }\end{array}$} & Alpha & 100 & (34) & 100 & (33) & 100 & (34) & 100 & (33) & 100 & (34) & 100 & (33) & - & - \\
\hline & Bravo & 0 & $(0)$ & 0 & $(0)$ & 0 & $(0)$ & 0 & $(0)$ & 0 & $(0)$ & 0 & $(0)$ & & \\
\hline & $\begin{array}{l}\text { Intergroup } \\
p \text { value }\end{array}$ & - & & & & - & & & & - & & & & & \\
\hline \multirow[t]{4}{*}{ Gross fracture } & Alpha & 100 & (34) & 100 & (33) & 100 & (34) & 100 & (33) & 100 & (34) & 100 & (33) & - & - \\
\hline & Bravo & 0 & $(0)$ & 0 & $(0)$ & 0 & $(0)$ & 0 & $(0)$ & 0 & $(0)$ & 0 & $(0)$ & & \\
\hline & Charlie & $100 \%$ & (34) & 100 & (33) & 100 & (34) & 100 & (33) & 100 & (34) & 100 & (33) & & \\
\hline & $\begin{array}{l}\text { Intergroup } \\
p \text { value }\end{array}$ & - & & & & - & & & & - & & & & & \\
\hline \multirow{4}{*}{$\begin{array}{l}\text { Anatomic } \\
\text { contour } \\
\text { (wear) }\end{array}$} & Alpha & 100 & (34) & 100 & (33) & 100 & (34) & 100 & (33) & 100 & (34) & 100 & (33) & - & - \\
\hline & Bravo & $0 \%$ & $(0)$ & 0 & $(0)$ & 0 & $(0)$ & 0 & $(0)$ & 0 & (0) & 0 & $(0)$ & & \\
\hline & Charlie & 100 & (34) & 100 & (33) & 100 & (34) & 100 & (33) & 100 & (34) & 100 & (33) & & \\
\hline & $\begin{array}{l}\text { Intergroup } \\
p \text { value }\end{array}$ & - & & & & - & & & & - & & & & & \\
\hline
\end{tabular}

\footnotetext{
*Significant $(p \leq 0.05)$; NS, non-significant $(p>0.05)$
} 


\section{Conclusion}

Both direct SFRC and indirect nanohybrid resin composite complex restorations showed an acceptable successful clinical performance along the 1-year follow-up period. Choosing between direct or indirect approach could depend on several factors as direct technique by bulk fill SFRC offers cost-effectiveness and ease of use but needs more operator skills and patient time, while the indirect technique offers better control during the anatomical buildup and less chairside patient time but more procedural steps and cost.

\section{References}

1. Opdam N, Frankenberger R, Magne P, et al. From "Direct vs Indirect" toward an integrated restorative concept in the posterior dentition. Oper Dent 2016;41(S7):S27-S34. DOI: 10.2341/15-126-LIT.

2. Pott $P$, Rzasa $A$, Stiesch $M$, et al. Internal and marginal fit of modern indirect class II composite inlays. J Dent Mater Tech 2014;3(3):99-105. DOI: 10.22038/JDMT.2014.2967.

3. Garoushi S, Mangoush E, Vallittu M, et al. Short fiber reinforced composite: a new alternative for direct onlay restorations. Open Dent J 2013;7(4):181-185. DOI: 10.2174/1874210601307010181.

4. Tsujimoto A, Barkmeier WW, Takamizawa T, et al. Mechanical properties, volumetric shrinkage and depth of cure of short fiberreinforced resin composite. Dent Mater J 2016;35(3):418-424. DOI: 10.4012/dmj.2015-280.

5. Garoushi S, Gargoum A, Vallittu PK, et al. Short fiber-reinforced composite restorations: a review of the current literature. J Investig Clin Dent 2018;9(3):e12330. DOI: 10.1111/jicd.12330.

6. Garoushi S, Tanner J, Vallittu P, et al. Preliminary clinical evaluation of short fiber-reinforced composite resin in posterior teeth: 12-months report. Open Dent J 2012;6(4):41-45. DOI: 10.2174/1874210601206010041.

7. Tanner J, Tolvanen M, Garoushi S, et al. Clinical evaluation of fiber-reinforced composite restorations in posterior teeth - results of 2.5 year follow-up. Open Dent J 2018;12(4):476-485. DOI: 10.2174/1874210601812010476.

8. Azeem RA, Sureshbabu NM. Clinical performance of direct vs indirect composite restorations in posterior teeth: a systematic review. J Conserv Dent 2018;21(1):2-9. DOI: 10.4103/JCD.JCD213_16.

9. Candan U, Eronat N, Onçağ O. Clinical performance of fiber-reinforced nanofilled resin composite in extensively carious posterior teeth of children: 30-month evaluation. J Clin Pediatr Dent 2013;38(1):1-6. DOI: $10.17796 / j c p d .38 .1 . q 352786473372282$.

10. Needleman I, Worthington $\mathrm{H}$, Moher $\mathrm{D}$, et al. Improving the completeness and transparency of reports of randomized trials in oral health: the CONSORT statement. Am J Dent 2008;21(1):7-12.
11. Ricketts $D$, Innes N, Schwendicke F. Selective removal of carious tissue. Monogr Oral Sci 2018;27:82-91. DOI: 10.1159/000487838.

12. Shor A, Nicholls JI, Phillips KM, et al. Fatigue load of teeth restored with bonded direct composite and indirect ceramic inlays in MOD class II cavity preparations. Int J Prosthodont 2003;16(1):64-69.

13. Opdam NJ, van de Sande FH, Bronkhorst E, et al. Longevity of posterior composite restorations: a systematic review and meta-analysis. J Dent Res 2014;93(10):943-949. DOI: 10.1177/0022034514544217.

14. Torres CRG, Mailart MC, Crastechini É, et al. A randomized clinical trial of class II composite restorations using direct and semidirect techniques. Clin Oral Investig 2019;24(2):1053-1063. DOI: 10.1007/ s00784-019-02999-6.

15. Marquillier T, Doméjean S, Le Clerc J, et al. The use of FDI criteria in clinical trials on direct dental restorations: a scoping review. J Dent 2018;68:1-9. DOI: 10.1016/j.jdent.2017.10.007.

16. Goracci C, Cadenaro M, Fontanive L, et al. Polymerization efficiency and flexural strength of low-stress restorative composites. Dent Mater 2014;30(6):688-694. DOI: 10.1016/j.dental.2014.03.006.

17. Qanungo A, Aras MA, Chitre V, et al. Immediate dentin sealing for indirect bonded restorations. J Prosthodont Res 2016;60(4):240-249. DOI: 10.1016/j.jpor.2016.04.001.

18. Auschill TM, Koch CA, Wolkewitz M, et al. Occurrence and causing stimuli of postoperative sensitivity in composite restorations. Oper Dent 2009;34(1):3-10. DOI: 10.2341/08-7.

19. da Veiga AM, Cunha AC, Ferreira DM, et al. Longevity of direct and indirect resin composite restorations in permanent posterior teeth: a systematic review and meta-analysis. J Dent 2016;54:1-12. DOI: 10.1016/j.jdent.2016.08.003.

20. Mendonça JS, Neto RG, Santiago SL, et al. Direct resin composite restorations vs indirect composite inlays: one-year results. J Contemp Dent Pract 2010;11(3):025-032.

21. Priyalakshmi S, Ranjan M. A review on marginal deterioration of composite restoration. IOSR J Dent Med Sci 2014;13(1):6-9.

22. Lu H, Powers JM. Color stability of resin cements after accelerated aging. Am J Dent 2004;17(5):354-358.

23. Nedeljkovic I, Teughels W, De Munck J, et al. Is secondary caries with composites a material-based problem. Dent Mater 2015;31(11): e247-e277. DOI: 10.1016/j.dental.2015.09.001.

24. Jokstad A. Secondary caries and microleakage. Dent Mater 2016;32(1):11-25. DOI: 10.1016/j.dental.2015.09.006.

25. Alvanforoush N, Palamara J, Wong RH, et al. Comparison between published clinical success of direct resin composite restorations in vital posterior teeth in 1995-2005 and 2006-2016 periods. Aust Dent J 2017;62(2):132-145. DOI: 10.1111/adj.12487.

26. American Dental Association. (2001). Council on Scientific Affairs. American Dental Association program guidelines: products for dentin and enamel adhesive materials. www.ada.org. 